\title{
Epilepsy and employment. A community based survey in an area of high unemployment
}

\author{
R D C Elwes, J Marshall, A Beattie, P K Newman
}

\begin{abstract}
A community based survey was undertaken to assess the work record of patients with epilepsy in an area of high unemployment. One hundred and thirty seven epileptic patients were identified from a population of 23837 persons of employable age registered with three urban group practices in North East England. The unemployment rate for economically active patients with epilepsy was $46 \%$ compared with $19 \%$ for an age and sex matched control population $(p<0.01)$. Fifty nine per cent of patients with active epilepsy were unemployed. In those with an associated neurological or psychiatric handicap and those who were unskilled manual workers the unemployment rates were $79 \%$ and $77 \%$, respectively. Patients with epilepsy were less likely to leave school with qualifications or undergo subsequent training or apprenticeships. They were more likely to be unskilled manual workers, single and living in rented accommodation. In an area of high unemployment patients with epilepsy have disproportionately greater difficulty finding work. High unemployment rates among patients with epilepsy are only one aspect of a spectrum of social and economic disadvantage.
\end{abstract}

Patients with epilepsy may have difficulty in finding and maintaining regular employment. They face appropriate restrictions, such as those relating to driving or working in situations in which they might be liable to injury. They may also be the victims of ignorance and stigmatisation. $^{1}$ A number of hospital and community based studies carried out in Britain have reported employment rates among patients with epilepsy (table 1). In 1958 Gordon and Russell ${ }^{2}$ found that $91 \%$ of patients with epilepsy attending the National Hospital were fully employed. Shortly after this, Crombie et $a l^{3}$ reported that $74 \%$ of patients with chronic epilepsy were fully employed and a further $12 \%$ were partly employed. Two subsequent studies reported lower employment rates, of the order of $60 \% .{ }^{45}$ The results are not strictly comparable as both looked at patients who had never experienced work difficulties at any time, rather than those who were unemployed at the time of the survey. As recently as 1980
Scambler and Hopkins ${ }^{6}$ have found that the employment rates among patients with epilepsy did not differ greatly from those derived from government statistics for the general population.

All these studies were carried out during a time of full employment. Since then unemployment rates have increased nationally from $5 \%$ in 1979 to $12 \%$ in 1986 . In the North East of England the rate is $16 \%$ whilst in parts of Teesside it has risen to over $20 \%$ giving this area one of the highest unemployment rates in the United Kingdom. ${ }^{7}$ During times of high unemployment it is likely that people with epilepsy, or indeed any chronic disabling illness, will have disproportionately greater difficulty finding work. We have conducted a community based survey of employment amongst patients with epilepsy identified from three urban group practices on Teesside. The social background, education and training attainments and subsequent work records were studied and compared with an age and sex matched control group identified from the same population.

\section{Methods}

All men aged 18 to 65 and women aged 18 to 60 who had a history of seizures were identified from the diagnostic indices of three group practices on Teesside. Each practice kept a continuously updated computerised database of diagnostic categories of all patients who were registered. Practices one and two were in central Middlesbrough and included an inner city area with high levels of social and economic deprivation. Practice three was in a residential area of Stockton with a broader social mix and in close proximity to one of the major employers in the area.

All patients were seen by a neurologist for diagnostic review. Only those with an undoubted history of two or more afebrile seizures were studied. Patients with seizures occurring in the context of alcohol abuse, acute metabolic or neurological disturbance and those with progressive neurological disorders were excluded. Each patient subsequently had a structured interview containing 58 questions. In addition to demographic and clinical details, the hospital referral practices, social background, educational and training attainments and subsequent work records were recorded. All previous jobs and periods of unemployment were noted. Each epileptic patient was matched with a control of the same age and sex chosen at random from the 
Table 1 Surveys of epilepsy and employment undertaken in the United Kingdom

\begin{tabular}{llll}
\hline Author & $\begin{array}{l}\text { Total number } \\
\text { of patients }\end{array}$ & $\begin{array}{l}\text { Percent } \\
\text { employed }\end{array}$ & Case selection \\
\hline Gordon and Russell 1958 & 400 & 91 & Outpatients at the National Hospital \\
Crombie et al 1960 & 940 & 74 & Sixty seven general practices in England and Wales \\
Pond and Bidwell 1960 & 157 & 60 & Fourteen general practices \\
Porter 1968 & 100 & 66 & Outpatients at the Central Middlesex Hospital \\
Scambler and Hopkins 1980 & 73 & $74^{\star}$ & Five general practices in and around London \\
& & $32 \dagger$ & \\
\hline
\end{tabular}

*Men

†Married women

†Single women

computerised index of the 23867 persons who were registered with the practices. Relevant medical details were recorded and a similar structured interview of social background, educational and training attainments and subsequent work record was administered.

Seizures were classified on clinical grounds in accordance with the criteria laid down by the International League Against Epilepsy. ${ }^{8}$ Inactive epilepsy was defined as a period of at least two years completely seizure free regardless of whether patients were receiving medication; symptomatic epilepsy as seizures occurring in the context of a known cerebral disorder likely to be associated with epilepsy. Neurological handicaps were defined as major deficits such as hemiparesis or cognitive impairment, and psychiatric handicap as a disorder of sufficient severity to warrant referral to a psychiatrist. The social class of all patients and controls was classified on the basis of most recent employment in accordance with the criteria used by the Registrar General. ${ }^{9}$ Those who were in Government Youth Training Schemes or had never worked were classsified by their father's occupation. Housewives and single parents who had no intention of undertaking paid employment and those who were retired, in full time education or registered disabled were considered to be economically inactive, in accordance with the criteria used by the Department of Employment. ${ }^{10}$

\section{Results}

Following diagnostic review 72 men and 65 women were identified who had experienced two or more afebrile seizures at some time during their life. One hundred and sixteen had previously been seen in a hospital outpatients department, 80 by a neurologist, 19 by a general physician and 17 by a paediatrician. Three of the controls had a significant non neurological illness that interfered with their work and one had a hemiparesis due to a previous stroke. None of the controls had epilepsy. Sixteen epileptic patients and five controls refused to be interviewed but it was possible to ascertain clinical and demographic details in all cases. Following enquiries through their family practitioners the current employment status was known in all but four of the epileptic patients.

The employment status of the epileptic patients and controls are summarised in table 2 . Forty seven of the epileptic patients (46\%) and 21 of the controls $(19 \%)$ were unemployed (Chi square $=18, \mathrm{p}<0.01$ ). Of the 47 epileptic patients who were unemployed 42 $(89 \%)$ had been out of work for more than a year compared with nine out of $21(43 \%)$ of the controls (Chi square $=14.4, \mathrm{p}<0.01$ ).

A number of clinical and social factors were analysed to assess their impact on employment rates among economically active patients with epilepsy. The unemployment rate for patients with active epilepsy was 59\% compared with $36 \%$ for patients who had not experienced a seizure within the previous two years (Chi square $=5.4, p<0.05$ ). Patients with an associated neurological or psychiatric handicap had an unemployment rate of $79 \%$, compared with $33 \%$ for patients with no such handicap (Chi square $=18, \mathrm{p}<0.01$ ). Seventy seven per cent of unskilled manual workers were out of work. Among those with professional, skilled and semiskilled occupations the unemployment rate was $7 \%, 41 \%$ and $33 \%$ respectively (Chi square $=12.3$, $\mathrm{p}<0.05)$. Age, sex, age at onset of epilepsy, seizure type, the timing of seizures, treatment status, the presence or absence of symptomatic epilepsy or the general practice with which the patient was registered were not significantly associated with the probability of being unemployed.

The social characteristics of the epileptic patients and matched controls are shown in table 3. Patients with epilepsy were less likely to leave school with qualifications or undergo subsequent training or apprenticeships. They were more likely to be single, live in rented accommodation, and be unskilled manual workers.

Table 2 The employment status of 137 epileptic patients compared with those of an age and sex matched control population

\begin{tabular}{lcc}
\hline & $\begin{array}{c}\text { Patients } \\
N(\%)\end{array}$ & $\begin{array}{c}\text { Controls } \\
N(\%)\end{array}$ \\
\hline Currently employed: & $55(54)$ & $90(81)$ \\
Full time & 46 & 70 \\
Part time & 7 & 19 \\
Youth training scheme & 2 & 1 \\
Currently unemployed & $47(46)$ & 21 \\
Unemployed >1 year & 42 & 9 \\
Unemployed <1 year & 5 & 12 \\
Sub total & $102(100)$ & $111(100)$ \\
Housewife/single parent & 16 & 9 \\
Retired & 4 & 8 \\
Full time education & 1 & 3 \\
Registered disabled & 10 & - \\
Unknown & 4 & 6 \\
Totals & $137(100)$ & $137(100)$ \\
\hline
\end{tabular}


Table 3 The social characteristics and educational attainments of 137 epileptic patients compared with those of an age and sex matched control population

\begin{tabular}{|c|c|c|}
\hline & $\begin{array}{l}\text { Epileptic } \\
\text { patients } \\
N(\%)\end{array}$ & $\begin{array}{l}\text { Controls } \\
N(\%)\end{array}$ \\
\hline $\begin{array}{l}\text { Median school leaving age, } \\
\text { years (range) }\end{array}$ & $16(14-18)$ & $16(14-18)$ \\
\hline $\begin{array}{l}\text { Yes } \\
\text { No } \\
\text { Unknown }\end{array}$ & $\begin{array}{l}42(31) \\
79(58) \\
16(11)\end{array}$ & $\begin{array}{l}70(51) \\
60(44) \\
7(5)\end{array}$ \\
\hline \multicolumn{3}{|l|}{$\begin{array}{l}\text { Subsequent training/ } \\
\text { apprenticeships }\end{array}$} \\
\hline $\begin{array}{l}\text { Yes } \\
\text { No } \\
\text { Unknown }\end{array}$ & $\begin{array}{l}38(28) \\
82(60) \\
17(12)\end{array}$ & $\begin{array}{r}67(49) \\
64(47) \\
6(4)\end{array}$ \\
\hline \multicolumn{3}{|l|}{ Higher education } \\
\hline $\begin{array}{l}\text { Yes } \\
\text { No } \\
\text { Unknown }\end{array}$ & $\begin{array}{r}8(6) \\
113(82) \\
16(12)\end{array}$ & $\begin{array}{r}10(7) \\
119(87) \\
8(6)\end{array}$ \\
\hline \multicolumn{3}{|l|}{ Social class } \\
\hline I & $2(2)$ & $6(4)$ \\
\hline II & $15(11)$ & $26(19)$ \\
\hline III, non-manual & $18(13)$ & $30(22)$ \\
\hline III, manual & $28(20)$ & $35(26)$ \\
\hline IV & $37(27)$ & $24(18)$ \\
\hline $\mathrm{v}$ & $28(20)$ & $4(3)$ \\
\hline Unknown & $9(7)$ & $11(8)$ \\
\hline \multicolumn{3}{|l|}{ Marital status } \\
\hline Single & $48(35)$ & $33(24)$ \\
\hline Married & $65(47)$ & $90(66)$ \\
\hline Divorced & $13(10)$ & $9(7)$ \\
\hline Unknown & $11(8)$ & $5(3)$ \\
\hline \multicolumn{3}{|l|}{ Housing } \\
\hline Rented & $65(47)$ & $25(18)$ \\
\hline Owner occupier & $57(42)$ & $106(77)$ \\
\hline Unknown & $15(11)$ & $6(5)$ \\
\hline \multicolumn{3}{|l|}{ Driver } \\
\hline Yes & $34(25)$ & $89(65)$ \\
\hline No & $87(64)$ & $41(30)$ \\
\hline Unknown & $16(11)$ & $7(5)$ \\
\hline
\end{tabular}

Fifty eight of the 121 subjects interviewed identified specific causes of disability at work. Restrictions due to working at heights or near unguarded machinery (19 cases) or inability to hold a driving licence (seven cases) were the most common. Fourteen patients thought that irrational attitudes of employers had led to unfair discrimination. This usually arose through immediate exclusion of a job application if epilepsy was mentioned at an interview. Other causes of disability included the presence of associated handicaps such as cognitive impairment (seven cases) or drug induced drowsiness (three cases). Less common causes were loss of educational or training opportunities due to epilepsy, difficulty in carrying out work due to frequent seizures and deteriorating seizure control following stress at work.

\section{Discussion}

These results contrast strongly with previous studies carried out in Britain which have shown that unemployment rates among epileptic patients do not appear to differ greatly from those of the general population (see table 1). The 137 patients in this study were identified from the diagnostic indices of three group general practices serving a total population of 23867 persons of employable age. Diagnostic indices for epilepsy, whether based on hospital or general practice records, are often unreliable $^{11}$ so each patient had a diagnostic review before being accepted into the study. It is possible that some cases of epilepsy were missed from the population under study as one practice only included on the diagnostic index those cases who were on medication and continuing to have seizures. Despite these difficulties a community based design ensured that a high proportion of cases with mild or inactive epilepsy were included in the study. Over half the patients had been free of seizures for two or more years and a quarter had stopped taking antiepileptic medication. The selection of patients with intractable seizure disorders and multiple handicaps found in hospital populations was avoided.

The most likely reason for the high unemployment rates found in this study was the adverse economic climate and difficult job market that existed locally. It is unlikely that other factors such as changes in employers' attitudes to epilepsy, eligibility for disability benefits, general employment policies or deficiencies in the public transportation system could explain the high unemployment rates. The subjects we studied repeatedly observed that given the fierce competition for available jobs a diagnosis of epilepsy led to automatic exclusion by a prospective employer. This appeared to be particularly so among unskilled manual workers where the unemployment rate was $77 \%$.

No previous survey of epilepsy and employment has included a control population. These were identified from the practice registers ensuring that local factors such as job availability were the same for both groups. The social class distribution of the controls and unemployment rate of $19 \%$ was very similar to those of the general population, ${ }^{7}$ suggesting that the sample was not biased. No attempt was made to control for other factors, such as the presence of neurological or psychiatric handicaps, as these form an integral part of epilepsy. Forty seven per cent of the epileptic patients were semiskilled or unskilled manual workers compared with $21 \%$ of the controls. In contrast the social class distribution of the fathers of the epileptic patients and controls were similar lending some support to the hypothesis that a drift towards lower socioeconomic class may occur in patients with epilepsy. ${ }^{12}$ Patients with epilepsy were also less likely to leave school with qualifications or undergo subsequent training or apprenticeships. They were more likely to be single and live in rented accommodation. The high unemployment rates among epileptic patients appeared to be only one aspect of a wider spectrum of social and economic disadvantage.

Much needs to be done to help the employment prospects of people with epilepsy, particularly during an economic depression when they experience disproportionately high unemployment rates. Myths that they make poor employees should be strongly refuted. Studies have repeatedly shown that injury rates, absenteeism, time lost due to illness and productivity for those in work are no different from those of the general population. ${ }^{13-16} \mathrm{~A}$ code of practice for job applications, similar to that used in the civil service, should be encouraged. ${ }^{17}$ Medical details should be kept separate on job application forms, and inspec- 
ted by those qualified to interpret them only after a decision on recruitment has been made on non medical grounds. Employers may need guidelines concerning suitability for particular types of work, either from the patient's doctor, the occupational health service or from government bodies such as the Health and Safety Executive. ${ }^{18} \mathrm{~A}$ small proportion of patients with epilepsy are severely disabled by frequent seizures or associated handicaps such as cognitive impairment and need sheltered employment. Employers should be encouraged to comply with established guidelines for the employment of disabled persons ${ }^{19}$ to achieve greater success in this area.

The authors are grateful for all the help and cooperation given by Drs Ian Ruffett, Geoffrey Stout, Roger Thornham and their partners.

1 Editorial. Epilepsy and Employment. BMJ 1985;291:2-3. 2 Gordon N, Russell S. The problem of unemployment among epileptics. J Ment Sci 1958;104:103-14.

3 Crombie DL, Cross KW, Fry J, Pinsent RJFH, Watts CAH. A survey of the epilepsies in general practice. A report by A survey of the epilepsies in general practice. A report by the Research Committee of the

4 titioners. BMJ 1960;2:416-22. 1968;1:83-90.

5 Pond DA, Bidwell BH. A survey of epilepsy in fourteen general practices. II. Social and Psychological aspects.
Epilepsia 1959/60;1:285-99.

6 Scambler G, Hopkins A. Social class, epileptic activity, and disadvantage at work. J Epidemiol Comm Health 1980; 34:129-33.

7 Central Statistical Office. Regional Trends. London, HMSO;1987.

8 Commission on Classification and Terminology of the International League against Epilepsy. Proposed for revised clinical and electroencephalographic classification of epileptic seizures. Epilepsia 1981;22:489-501.

9 General Register Office. Classification of occupations. London, HMSO, 1966.

10 Central Statistical Office. Social Trends 18. London, HMSO;1988:201-2.

11 Sander JWAS, Shorvon SD. Incidence and prevalence studies in epilepsy and their methodological problems: review. J Neurol Neurosurg Psychiatry 1987;50:829-39.

12 Office of Health Economics. Epilepsy in society. London Office of health economics, 1971.

13 Udel MM. The work performance of epileptics in industry. Archives of Environmental Health 1960;1:91-8.

14 Lione JG. Convulsive disorders in a working population. $J$ Occupat Med 1961;3:369-73.

15 MacIntyre I. Epilepsy and employment. Community Health 1976;7:195-204.

16 Dasgupta AK, Saunders M, Dick DJ. Epilepsy in the British Steel Corporation: an evaluation of sickness, accident and work records. BJIM 1982;39:145-8.

17 Espir M, Floyd M. Epilepsy and recruitment. In: Edwards F, Espir M, Oxley J, eds. Epilepsy and employment. A medical symposium on current problems and best practices. London: RSM, 1986. (Int congress and symposium series, 86).

18 Craig A, Oxley J. Statutory and non-statutory barriers to the employment of people with epilepsy. In: Edwards F, Espir $\mathrm{M}$, Oxley J, eds. Epilepsy and employment. A medical symposium on current problems and best practices. London: RSM, 1986. (Int congress and symposium series, 86)

19 Manpower Services Commission. Code of good practice on the employment of disabled people. MSC, Sheffield 1984.

\section{Aretaeus of Cappodocia (130-200)}

Aretaeus was the first to describe the aura and hallucinations preceding epilepsy and noted the tendency of seizures to recur once established. He differentiated nervous diseases and mental disorders, described hysteria, headache, mania and melancholia. The cerebral paralyses were closely studied and he observed that in a cerebral lesion the paralyses was crossed, but this was not the case with a spinal lesion. This was explained in terms of decussation of nerves.

This recent stamp (1990, Stanley Gibbons 249) was issued by Transkei as part of "The conquest of diabetes series." Aretaeus gave an early account of the disorder.

L F HAAS

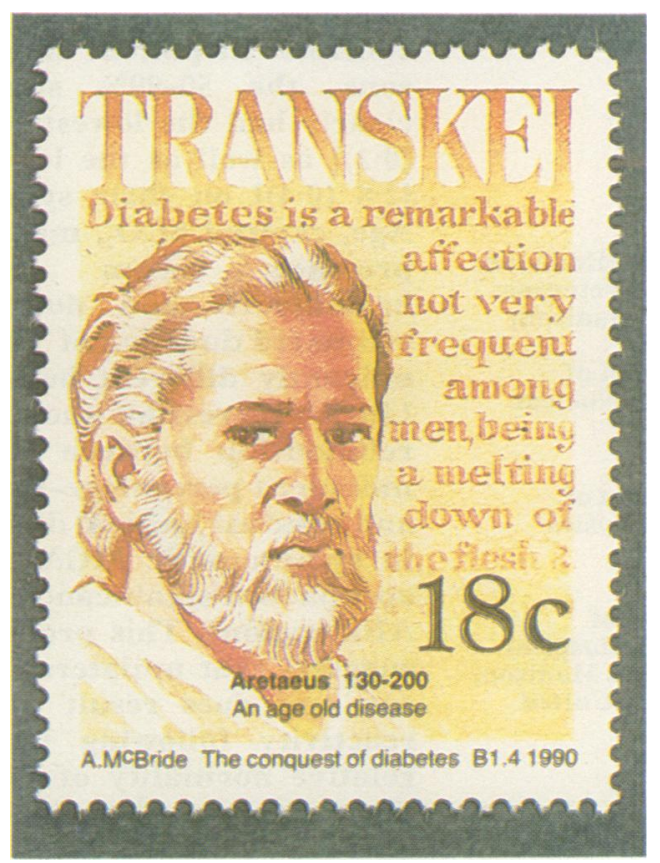

